\title{
Additional educational needs in children born to mothers with epilepsy
}

\author{
N Adab, A Jacoby, D Smith, D Chadwick
}

\begin{abstract}
Objectives-To examine the relative risks of additional educational needs (AENs) in children exposed to antiepileptic drug (AED) monotherapy and polytherapy regimes in utero.

Methods-A retrospective survey of women between the ages of 16 to 40 registered at the Mersey Regional Epilepsy Clinic, who received a postal questionnaire concerning their experience of pregnancy and the subsequent schooling of live-born children.
\end{abstract}

Results-721 (57\%) women of the 1267 approached returned an adequately completed questionnaire; $330(46 \%)$ had given birth to at least one live-born child. Information was collected on 594 children, 400 of whom were of school age (4-18). 150 $(37.5 \%)$ had been exposed to monotherapy in utero, $74(18.5 \%)$ were exposed to polytherapy, and 176 were not exposed to any AEDs. The odds ratio of AENs for all children exposed to AEDs in utero compared with those unexposed was 1.49 (95\% confidence interval (95\% CI) $0.83-2.67)$. Odds ratios for AENs for each therapy subgroup compared with those unexposed were also calculated for all children. Those exposed to valproate monotherapy had an odds ratio of 3.4 (95\% CI 1.63-7.10) by contrast with an odds ratio of 0.26 (95\% CI 0.061.15) for carbamazepine. Polytherapy including valproate had similarly high odds ratios for AENs compared with those unexposed of 2.51 ( 95\% CI 1.04-6.07) versus the odds ratio of 1.51 ( $95 \%$ CI 0.56-4.07) for polytherapy excluding valproate.

Conclusions-Although the findings should be treated with caution, they suggest that monotherapy or polytherapy with valproate during pregnancy carries particular risks for the development of children exposed in utero.

(F Neurol Neurosurg Psychiatry 2001;70:15-21)

Keywords: epilepsy; pregnancy outcomes; teratogen

About one third of people receiving antiepileptic drugs (AEDs) are women of reproductive age $^{1}$ and one in 250 pregnancies may be exposed to AEDs. ${ }^{2}$ The risk of uncontrolled seizures in the mother conflicts with the potential risks of the medication to the fetus which include an increased risk of stillbirths, ${ }^{3}$ perinatal mortality, ${ }^{4}$ and intrauterine growth retardation. ${ }^{5}$ Similarly, there is a clear association with an increase in the number of major malformations ${ }^{6-8}$ and minor anomalies. ${ }^{9-11} \mathrm{Al}-$ though estimates of risk vary, there may be a twofold to threefold increase in congenital malformations among babies born to women with epilepsy compared with the general population. ${ }^{6}$ This makes management decisions problematic. It is difficult to disentangle the relative contribution of the epilepsy itself, seizure frequency during pregnancy, socioeconomic factors, and the teratogenicity of AEDs to this.

The most common major malformations described have included congenital heart disease, cleft lip or palate, limb defects, genitourinary malformations, and neural tube defects. ${ }^{6}$ Only neural tube defects have been specifically associated with sodium valproate ${ }^{12}$ and carbamazepine. ${ }^{13}$ Many investigators have proposed that a characteristic combination of minor anomalies may be specific to certain AEDs. ${ }^{14-17}$ However, there is considerable overlap among these, and the existence of drug specific syndromes has been questioned. ${ }^{11}$

Long term follow up of children exposed to AEDs in utero has been limited, so that relatively little is known about the subsequent neurological and cognitive development of these children. It has been difficult to apply these studies to current clinical practice as many of those reported in the literature have tended to be on polypharmacy, or have been taking drugs that are no longer commonly used. Due to the few pregnant women exposed to specific drugs, it has not been possible to make meaningful comparisons of risk between drugs. This is reflected in the clinical guidelines, which do not give specific recommendations about which of the most commonly used AEDs carry the most risk to pregnancy and the child. ${ }^{18}{ }^{19}$ With the rapid introduction of new drugs, prescription patterns have changed and there is a need to develop satisfactory methods to examine the relative risks of both new and old AEDs.

In this preliminary retrospective study we conducted a survey to compare the proportion of school age children exposed to different drug regimes, who had additional educational needs with or without physical disability born to mothers with epilepsy.

Methods

The Mersey Regional Epilepsy Clinic (MREC), established in 1989, has evolved into one of the largest multidisciplinary epilepsy services in the United Kingdom. In addition to serving Merseyside and North Wales, it accepts referrals from several other regions. The patient database $(n=5500)$ contains simple 
demographic data and clinical information on type of seizure and epilepsy, and drug treatment.

As a preliminary step in a study to ascertain detailed maternal and children's cognitive status, a postal questionnaire was sent to all women, between the ages of 16-40 in 1998, registered at the MREC, who did not have a history of a fixed severe neurological deficit, progressive neurological disease, or significant learning difficulties. The aims of the study were to establish the numbers of women with pregnancies exposed to AEDs and to examine the relation between such exposure and educational outcome in their children. We used questions about attendance at special schools, "statementing", or requirements for any extra help within mainstream schooling as an indicator of additional educational needs. When a child is identified as having additional needs in school, a five stage process of assessment and review is implemented depending on the degree of help required. A statement of additional educational need is given to those children with particularly severe needs that are not met with simple measures and may relate to acquired or congenital physical disabilities, behavioural problems, or cognitive impairment. Supplementary questions allowed us to identify the children with predominantly physical disabilities.

Data were collected on:

(1) The number of women with pregnancies exposed to AEDs. The main issues considered were the number of live births, stillbirths, spontaneous miscarriages, and terminations. Supplementary questions assessed the number of AEDs taken, if any, during these pregnancies.

(2) The personal seizure history of the mothers was recorded including the age of onset of seizure disorder, seizure frequency, and number of drugs at the time of questioning. The mothers were also asked to note any other personal medical problems.

(3) The date of birth of any live born children, their birth weight, exposure to AEDs, and duration of exposure during pregnancy were also recorded. Drug exposure was checked against hospital records in a sample of 100 children.

(4) The number of school age children at the time of questioning with additional educational needs (AENs), including those requiring extra help in mainstream school. In addition the number of children receiving a statement for additional educational needs was determined.

(5) Open ended questions were used to ask mothers about the number of children requiring surgery or specialist hospital management as a measure of major congenital malformations. Only those that could clearly be categorised into broad groups of accepted congenital malformations were considered.

The questionnaire was approved by the local ethics committee and the information collected was treated as confidential. The results were double entered into a computerised database (Microsoft Access).
DATA ANALYSIS

Odds ratios and 95\% confidence intervals (95\% CIs) were calculated for any form of additional educational needs in those children exposed to antiepileptic drugs compared with those that were not. Further analysis was undertaken comparing different monotherapy regimes where numbers made this meaningful. To explore the bias introduced by inclusion of siblings, odds ratios for AENs according to drug exposure subgroup compared with those unexposed were also calculated in the first born child.

\section{Results}

A total of 1350 women was identified initially. After exclusion of 64 women who did not have epilepsy, and a further 19 who had significant learning difficulties or severe neurological deficit, 1267 women were contacted. Nonresponders were sent two reminders, separated by 6 to 8 weeks. Seven hundred and twenty one (57\%) adequately completed questionnaires were returned.

\section{THE MOTHERS}

Among responders, 376 women (52\%; 95\% CI $49-56 \%$ ), with a mean age of 31.2 years (range 18-40 (SD 5.6) years), had experienced pregnancy and 330 (46\%; 95\% CI 42-49\%) had at least one live birth. Seven women were pregnant at the time of questioning. Thirty two per cent (95\% CI $28-38 \%)$ were seizure free in the year before the survey, and $13 \%$ (95\% CI 9-16\%) were not on any AEDs at the time of contact. One hundred and six $(28 \%)$ women had additional medical problems, with the commonest problems being asthma, arthritis, irritable bowel syndrome, and thyroid disease. Eight women $(2 \%)$ had a cerebral tumour as the cause of their seizures but did not have a neurological deficit.

\section{NON-RESPONDERS}

The mean age of non-responders (546) was 29 years (range 16-40 (SD 6)). Further details were sought for a random sample of 54 non-responders by examining case notes and direct contact where possible, to compare them with responders. One was not traceable, and a further 16 would have been excluded on the basis of the further information obtained (13 did not have a diagnosis of epilepsy and three had severe learning difficulties). Of the remaining $37,41 \%$ had changed address and had not received the questionnaire. Of the 37, 20 (54\%; 95\% CI 37-70\%) had been pregnant at some point and $17(46 \%$; 95\% CI 30-62\%) had had at least one live-born child. Twenty four per cent $(95 \%$ CI $10-38 \%)$ were seizure free in the year before the questionnaire and 16\% (95\% CI $5-28 \%$ ) were not on any AEDs at the time of the questionnaire.

THE CHILDREN

The number of children born to each mother ranged between one and six, with a median of two (interquartile range 1-3) (table 1). Information was collected for 594 children aged between 3 months and 23 years (mean age 8.95 


\begin{tabular}{|c|c|}
\hline Children (n) & Mothers (n) \\
\hline 1 & 140 \\
\hline 2 & 134 \\
\hline 3 & 33 \\
\hline 4 & 14 \\
\hline 5 & 5 \\
\hline 6 & 1 \\
\hline
\end{tabular}

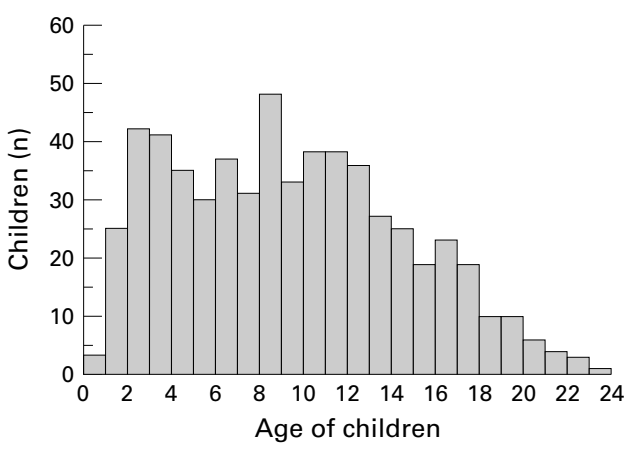

Distribution of children's ages. Histogram showing the number of children of various ages.

(SD 5.18)) (figure). Nearly a quarter (145, $24 \%$ ) were younger than 5 , and $400(67.3 \%)$ were between the ages of 5 and 18 (school age).

EXPOSURE TO DRUGS

Information about exposure to AEDs in utero was available for 590 of the children, including all 400 school age children. Of the 400, 150 $(37.5 \%)$ had been exposed to monotherapy in utero, $74(18.5 \%)$ were exposed to polytherapy, and 176 were not exposed to any AEDs. The reasons for non-exposure were either that maternal pregnancy predated the diagnosis or onset of epilepsy $(118,67 \%)$, or there was a history of epilepsy which no longer required treatment $(58,37 \%)$.

Any change in antiepileptic drug treatment during pregnancy in our sample was minimal. Six pregnancies involved a switch in medication or addition of a further drug. These were treated as pregnancies exposed to polytherapy with the particular drugs in question. Fifteen pregnancies involved exposure to AEDs in the first trimester only and a further 17 pregnancies involved exposure from the second trimester onwards. Exposure throughout the pregnancy compared with exposure during just a part of pregnancy was treated in the same way in our subsequent analysis.

The proportion of children exposed to different monotherapy and polytherapy regimes in utero is shown for all children and children of school age (tables 2 and 3). The commonest monotherapy exposure in utero for school age children was carbamazepine (42\%) and valproate $(37.3 \%)$. The polytherapy re- gimes were wide ranging, with the commonest regimes being carbamazepine and valproate $(28.4 \%)$, carbamazepine and phenytoin $(17.5 \%)$, and valproate and phenytoin $(8.1 \%)$. Eight $(10.8 \%)$ of the children had been exposed to three or more drugs. The drug exposure during pregnancy was checked against hospital records in all children with additional educational needs and a sample of other children (total of 100) showing 96\% accuracy.

EDUCATIONAL OUTCOME IN CHILDREN

Among the 594 children 400 were currently attending school. The majority, 349 (87.25\%), attended mainstream school without formal additional educational help. Of the remainder, $42(10.5 \%)$ attended mainstream school but required remedial help, eight $(2 \%)$ attended a special day school, and one $(0.25 \%)$ attended a special residential school. Among all children $33(8.25 \%)$ had been given a statement of special educational needs during their schooling, although five were attending a mainstream school without any extra help at the time of questioning. The type of school and requirements for additional help are shown by drug exposure in utero (tables 4 and 5). All children requiring extra help in mainstream school, at special school, or given a statement, were grouped as children with additional educational needs (AENs). Only six of the children with additional educational needs had significant physical disability.

The mean age of children with any type of AEN was 10.1 years (95\% CI 9.1-11.1) while the mean age of the subgroup with statements was 10.8 years (95\% CI 9.45-12.23) and for those in mainstream school it was 10.6 years (95\% CI 10.2- 11.0).

The odds ratio for AENs of any kind, for all the children exposed to AEDs, compared with those that were unexposed, was 1.49 (95\% CI 0.83-2.67) (table 6). There were six pairs of siblings among the group where both exhibited AENs. To explore the bias of including siblings, the odds ratio was calculated separately for the first-born child giving a value of 0.98 (CI $0.44-$ 2.19).

Table 2 Drug exposure during pregnancy: monotherapy exposure in utero

\begin{tabular}{lccccccc}
\hline \multicolumn{7}{c}{ Antiepileptic drugs used in monotherapy } \\
\cline { 2 - 7 } & Lamotrigine & Carbamazepine & $\begin{array}{l}\text { Sodium } \\
\text { valproate }\end{array}$ & Phenytoin & Phenobarbital & Ethosuximide & Total \\
\hline School age children (n (\%)) & $5(3.3)$ & $63(42)$ & $56(37.3)$ & $22(14.7)$ & $4(2.7 \%)$ & 0 & 150 \\
All children exposed (n (\%)) & $13(5.1)$ & $116(44.9)$ & $95(37.5)$ & $24(9.4)$ & $7(2.7 \%)$ & $1(0.4)$ & 256 \\
\hline
\end{tabular}

Table 3 Drug exposure during pregnancy: polytherapy exposure in utero

\begin{tabular}{|c|c|c|c|c|c|c|c|c|}
\hline & \multicolumn{4}{|c|}{ Polytherapy regimes } & \multicolumn{4}{|l|}{ Total } \\
\hline & $\begin{array}{l}\text { Valproate+ } \\
\text { carbamazepine }\end{array}$ & $\begin{array}{l}\text { Valproate+ } \\
\text { lamotrigine }\end{array}$ & $\begin{array}{l}\text { Valproate+ } \\
\text { phenytoin }\end{array}$ & $\begin{array}{l}\text { Carbamazepine+ } \\
\text { phenytoin }\end{array}$ & $\begin{array}{l}\text { Carbamazepine } \\
+ \text { vigabatrin }\end{array}$ & Miscellaneous & Triple therapy & \\
\hline School age children exposed (n (\%)) & $21(28.4)$ & $2(2.7)$ & $6(8.1)$ & $13(17.5)$ & $3(4.05 \%)$ & $21(28.4 \%)$ & $8(10.8 \%)$ & 74 \\
\hline All children exposed (n (\%)) & $22(20.0)$ & $8(7.2)$ & $9(8.2)$ & $14(12.7 \%)$ & $7(6.4 \%)$ & $37(33.6 \%)$ & $13(11.8 \%)$ & 110 \\
\hline
\end{tabular}

Drug exposure is shown in all liveborn pregnancies. 
Table 4 Type of school attended according to drug exposure

\begin{tabular}{lllll}
\hline Drug exposure & $\begin{array}{l}\text { Mainstream } \\
\text { school }\end{array}$ & $\begin{array}{l}\text { Mainstream } \\
\text { school with } \\
\text { extra help }\end{array}$ & $\begin{array}{l}\text { Special day } \\
\text { school }\end{array}$ & $\begin{array}{l}\text { Special } \\
\text { residential } \\
\text { school }\end{array}$ \\
\hline No drugs & 158 & $17 \ddagger$ & 1 & 0 \\
$\begin{array}{l}\text { Monotherapy: } \\
\quad \text { Valproate }\end{array}$ & 40 & 12 & $4^{\star}$ & 0 \\
$\quad$ Carbamazepine & 61 & 2 & 0 & 0 \\
$\quad$ Others & 30 & 1 & 0 & 0 \\
Polytherapy: & 28 & $6 \dagger$ & $2^{\star} \dagger$ & $1 \dagger$ \\
$\quad$ Including valproate & 32 & 4 & 1 & 0 \\
$\quad$ Other combinations & 349 & 42 & 8 & 1 \\
Total & & &
\end{tabular}

Symbols indicate a single child with: ${ }^{\star}$ spina bifida with hydrocephalus; †cerebral palsy; ¥brain haemorrhage age 6

Table 5 Statements of additional educational need according to drug exposure in utero

\begin{tabular}{|c|c|c|c|c|c|}
\hline Drug exposure & $\begin{array}{l}\text { Mainstream } \\
\text { school }\end{array}$ & $\begin{array}{l}\text { Mainstream } \\
\text { school with } \\
\text { extra help }\end{array}$ & $\begin{array}{l}\text { Special day } \\
\text { school }\end{array}$ & $\begin{array}{l}\text { Special } \\
\text { residential } \\
\text { school }\end{array}$ & $\begin{array}{l}\text { Total number } \\
\text { with } \\
\text { statements }\end{array}$ \\
\hline No drugs & 2 & $7 \ddagger$ & 1 & 0 & 10 \\
\hline \multicolumn{6}{|l|}{ Monotherapy } \\
\hline Valproate & 1 & 5 & $4^{\star}$ & 0 & 10 \\
\hline Carbamazepine & 0 & 0 & 0 & 0 & 0 \\
\hline Others & 1 & 1 & 0 & 0 & 2 \\
\hline \multicolumn{6}{|l|}{ Polytherapy } \\
\hline Including valproate & 0 & $3+$ & $2^{\star}+$ & $1+$ & 6 \\
\hline Other combinations & 1 & 3 & 1 & 0 & 5 \\
\hline Total & 5 & 19 & 8 & 1 & 33 \\
\hline
\end{tabular}

Symbols indicate a single child with: *spina bifida with hydrocephalus; †cerebral palsy; łbrain haemorrhage age 6

Table 6 Additional educational needs according to drug exposure subtype. All children

\begin{tabular}{lccl}
\hline Type of drug exposure & $\begin{array}{l}\text { Mainstream } \\
\text { school }\end{array}$ & Additional needs * & $\begin{array}{l}\text { Odds ratiof } \\
(95 \% \mathrm{CI})\end{array}$ \\
\hline No drugs & 156 & 20 & 1.0 \\
$\begin{array}{l}\text { Monotherapy } \\
\quad \text { Valproate }\end{array}$ & 39 & 17 & $3.40(1.63-7.10)$ \\
$\quad$ Carbamazepine & 61 & 2 & $0.26(0.06-1.15)$ \\
$\quad$ Others & 29 & 2 & $0.54(0.12-2.44)$ \\
Polytherapy & 28 & 9 & $2.51(1.04-6.07)$ \\
$\quad$ Including valproate & 31 & 6 & $1.51(0.56-4.07)$ \\
$\quad$ Other combinations & 344 & 56 & \\
Total & &
\end{tabular}

Overall odds ratio of AEN in all children exposed to any AED compared with those unexposed was 1.49 (95\% CI $0.83-2.67)$.

*Any form of additional educational need is included. This includes five children attending mainstream school without additional help who had received a statement of special educational needs. tOdds ratio of additional educational needs of each subgroup exposed to AEDs compared with those unexposed.

EFFECT OF SPECIFIC AED REGIMES IN ALL

CHILDREN

Subgroup analyses were performed to compare the proportion of all children with AENs according to AED exposure (table 6). Odds ratios of AENs for those exposed to valproate monotherapy compared with children unexposed was 3.40 (95\% CI 1.63-7.10) by contrast with 0.26 (95\% CI 0.06-1.15) for carbamazepine and 0.54 (95\% CI 0.12-2.44) for other monotherapy groups. The odds ratio for AENs was 1.98 (0.95-4.12) for any form of polytherapy compared with no drug exposure as opposed to 1.27 (95\% CI 0.66-2.45) for monotherapy. Polytherapy including valproate showed a higher odds ratio for AENs of 2.60 (95\% CI 1.07-6.31) than for polytherapy excluding valproate, 1.46 (95\% CI 0.54-3.92), although the confidence intervals overlapped. The odds ratios were not altered significantly by reclassifying the five children with statements in mainstream school with children attending mainstream school only.

EFFECT OF SPECIFIC REGIMES IN FIRST BORN CHILD There were six pairs of siblings where both had AENs. To explore bias introduced by inclusion of siblings, odds ratios for AEN according to drug exposure compared with those that were unexposed were calculated in the first-born child. The odds ratio for valproate monotherapy exposure was 1.89 (95\% CI 0.645.61) for the first born, compared with 0.19 (95\% CI 0.02-1.52) for carbamazepine. The odds ratios did not reach statistical significance for either drug, and the differences in odds ratios were smaller than for all children, indicating that sibling relationship may have some impact on our results. Nevertheless the trend for increased risk is still seen for first-born children exposed to valproate

\section{SEIZURE SEVERITY}

We did not request information about seizure frequency during pregnancy as it was thought that this would be unreliable. Seizure frequency at the time of questioning was taken as a surrogate marker for epilepsy severity in general. A $\chi^{2}$ test for trend showed a relation between AED monotherapy taken during pregnancy and current seizure frequency $\left(\chi^{2}\right.$ 4.87; df $1 ; \mathrm{p}=0.027)$. Of the mothers on valproate during pregnancy $41 \%$ had frequent seizures (defined as more than one seizure a month) at the time of questioning, while $60 \%$ of those on carbamazepine and $45 \%$ of those on other drugs had frequent seizures (table 7 ).

MATERNAL AGE

The mean age of mothers on no medication at the time of pregnancy was 22.9 years (95\% CI 22.3-23.5), whereas the mean ages for those taking sodium valproate, carbamazepine, and other drugs were 23.9 (95\% CI 23.0-24.9), 23.8 (95\% CI 22.6-25.0), and 24.2 years (CI 22.7-25.7) respectively.

The mean maternal age at birth of children with subsequent additional needs was 23.1 years (95\% CI 21.8-24.3), and the mean maternal age for those in subsequent normal school was 23.4 years (95\% CI 23.0-23.9).

Table 7 Seizure frequency at time of survey in relation to monotherapy regime taken in pregnancy

\begin{tabular}{|c|c|c|c|c|}
\hline & \multicolumn{4}{|c|}{ Seizure frequency } \\
\hline & No seizures & $\begin{array}{l}\text { Less than one } \\
\text { seizure /month }\end{array}$ & $\begin{array}{l}\text { One or more } \\
\text { seizures/ month }\end{array}$ & $\begin{array}{l}\text { Total number of mothers } \\
\text { with particular AED regime }\end{array}$ \\
\hline Valproate monotherapy ${ }^{\star}$ & 25 & 7 & 22 & $54^{\star}$ \\
\hline Carbamazepine monotherapy & 13 & 12 & 38 & 63 \\
\hline Other drug groups & 11 & 6 & 14 & 31 \\
\hline Total number of mothers with different seizure frequencies & 49 & 25 & 74 & 148 \\
\hline
\end{tabular}

$\star$ Total number of school age children exposed to valproate monotherapy $=56$; the current seizure frequency was missing for two of the pregnancies. 
Discussion

Over $90 \%$ of pregnancies in women with epilepsy proceed without problems, ${ }^{20}$ yet women are at increased risk of adverse outcomes. Congenital malformations have been the most commonly reported events and several studies support a teratogenic role for AEDs. ${ }^{21-24}$ These have failed to show any significant differences in teratogenic potential among the AEDs available. There has been growing concern that major congenital anomalies may simply represent the tip of an iceberg. ${ }^{25}$ Many case series and reports have suggested a characteristic pattern of minor dysmorphic features in children exposed to AEDs. ${ }^{14-17}$ These have included characteristic appearances of the eyes (epicanthal folds, hypertelorism), nose (flat nasal bridge, long philtrum), mouth (microstomia, prominent lower lip), and digits (distal phalangeal hypoplasia and nail hypoplasia). ${ }^{11}{ }^{26}$ These reports have also suggested a high prevalence of developmental delay, but have often been limited to a selected population of children seen by paediatricians and geneticists. Although several larger studies have compared children exposed to specific AEDs with controls, ${ }^{27-29}$ it has been difficult to determine the incidence of these dysmorphic and developmental problems.

A growing number of both retrospective $^{213031}$ and prospective studies ${ }^{32-40}$ have found a higher prevalence of developmental delay, especially in the first 2 years of life, in children born to mothers or fathers with epilepsy compared with population controls. There have been few studies with longer term follow up of exposed children up to preschool or school age. ${ }^{427-29}{ }^{40-43}$ Although some authors have found a trend towards an increase in cognitive impairment in exposure to polytherapy ${ }^{3240445}$ or high doses of AEDs, ${ }^{38} 39$ most studies have failed to show a differential effect between specific drugs. When specific AEDs have been implicated, the results have often been conflicting. In a prospective study, Hattig et $a l^{40}$ reported a higher incidence of cognitive impairment in children exposed to valproate. On further follow up of a subgroup exposed to monotherapy regimes only, they found a higher incidence of hyperexcitability in neonates and subsequent poorer neurological performance at pre-school age in the group exposed to valproate. ${ }^{46}$ However, the number exposed to valproate was small (eight).

Our retrospective study provides some insights into the risk of AENs in one of the largest populations of children born to mothers with epilepsy exposed to specific drugs. A simple retrospective questionnaire format allowed us to ascertain the proportion of children with AENs across a broad age range, whether attending a normal school, special day, or residential school. We achieved a 57\% response rate, which is slightly lower than other surveys of people with epilepsy that we have conducted. ${ }^{47}$ Information from a random sample of non-responders showed that a high proportion had changed address, making contact difficult. There were, however, no significant differences in the proportion of mothers who had been pregnant, or the severity of their seizure disorder for seizure frequency or number of AEDs taken.

A high proportion of women in our survey were not taking any AEDs during their pregnancy, due to the pregnancy preceding the diagnosis or onset of epilepsy (67\%), or alternatively a history of epilepsy not requiring treatment at that time (33\%). They represent a useful comparative group, who may share a genetic predisposition although, arguably one with a selection bias for less severe epilepsy syndromes than women taking treatment during pregnancy. Of the women taking AEDs at the time of pregnancy, over two thirds were on monotherapy, with most being on carbamazepine or sodium valproate. There was no evidence for effect of maternal age on prescribing practices.

Among the school age children, there were 33 children $(8.25 \%$ of the school age population surveyed, $5.7 \%$ of those not exposed to drugs, and $10.3 \%$ of those exposed to AEDs in utero) who had received a statement for additional educational needs. This seems higher than the proportion of school age children (age 3-19) receiving statements locally in Liverpool, which reached 3.1\% in 1998 (Liverpool Education Authority, Department of Additional Needs; personal communication). However, rates varied in the wider geographical region, being between $2.6 \%$ $5.1 \%$. By contrast, examining the data for specific drug regimes showed that much of the risk for AENs among those exposed to monotherapy or polytherapy might be accounted for by valproate exposure. Thirty per cent of those exposed to valproate monotherapy in utero had AENs compared with $3.2 \%$ and $6.5 \%$ of those exposed to carbamazepine and other monotherapy groups respectively. This generates a hypothesis that valproate as an individual drug carries particular risks to learning and development of children. The well identified risks of neural tube defects and a foetal valproate syndrome may be the tip of the iceberg. In agreement with our findings, Ohtsuka et al recently reported a prospective case-control study in which the odds ratio of developmental disorders was almost 10 times higher in those exposed to valproate monotherapy in utero than in those who were not. ${ }^{48}$

The retrospective nature of our results means that they must be interpreted with caution. Our response rate could be criticised for being too low, but undoubtedly factors contributing to the response rate were the mobility of the population of young adults and the failure of women without children to make "nil" returns. As we have in all cases made comparisons against unexposed children we hope we have avoided too many potential biases. Maternal reporting of educational outcome may be unreliable, and the population we have identified needs to be further investigated. We cannot exclude the possibility that treatment with valproate during pregnancy identifies a group of mothers who are at coincidentally high risk. The methods used should have excluded mothers with significant learning disability but not necessarily those with more subtle 
problems. Valproate is most commonly used as a first choice treatment for idiopathic generalised epilepsies in the population we studied. Indeed 22 of the 56 children with AENs had mothers with definite idiopathic generalised epilepsies. These genetic disorders could be linked to genetically determined learning disabilities, but there is no literature to support this. Certainly, using current seizure status as a surrogate for severity of epilepsy, women with pregnancies exposed to valproate did not seem to have a notably more therapy resistant or severe seizure disorder compared with those receiving carbamazepine,. A prospective study with seizure recording would be essential to adequately examine a possible confounding role of seizures during pregnancy.

We cannot comment on whether the risk of AENs is influenced by drug dosage and whether some lower valproate doses might be safe, nor whether parental IQ or psychosocial factors may have influenced our results. This will require further study. Similarly, we cannot discount the effect of recall bias, although this would seem to be an unlikely explanation for our results. The number of children exposed to drugs other than carbamazepine and valproate were very small and therefore meaningful statements about the other drugs could not be made.

The results of our study demand further urgent investigation to clarify and optimise treatment for women with epilepsy who are of childbearing age. We are in the process of conducting a large study of the population of children and their mothers that we have identified to quantify and characterise their formal cognitive abilities and to investigate the contribution of maternal IQ, seizure experience during pregnancy, and epilepsy type to educational outcome of children. Importantly, adequately sized, prospective controlled cohort studies are needed to quantify risk associated with individual drugs commonly used to treat epilepsy including newer antiepileptic drugs. Valproate has been in use in the United Kingdom for 25 years. We must ensure that women with epilepsy are adequately advised about the safety of new AEDs as fast as possible.

DWC and DS have received hospitality and support from al pharmaceutical companies manufacturing licenced drugs in the United Kingdom. The funding for this study was from internal departmental funds. NA is currently employed as a research registrar on a grant from Janssen-Cilag.

1 Yerby MS. Pregnancy, teratogenesis and epilepsy. Neurol Clin 1994;12:749-71.

2 Lindhout D, Omitzigt JGC. Pregnancy and the risk of teraLindhout D, Omitzigt JGC. Pregnancy and the

3 Yerby MS, Cawthon L. Mortality rates in infants of mothers with epilepsy [abstract]. Ann Neurol 1994:36:330.

4 Nelson KB, Ellenberg JH. Maternal seizure disorder, outcome of pregnancy and neurological abnormalities in children. Neurology 1982;32:1247-54.

5 Yerby MS, Koepsell T, Daling J. Pregnancy complications and outcomes in a cohort of women with epilepsy. Epilepsia 1985;26:631-5

6 El-Sayed YY. Obstetric and gynaecological care of women with epilepsy. Epilepsia 1998;39(suppl 18):S17-S25.

7 Koch S, Hartmann AM, Jager-Roman E, et al. Major malformations in children of epileptic parents-due to epilepsy or its therapy? In: Janz D, Dam M, Richens A, et al, eds. Epilepsy, pregnancy and the child. New York: Raven Press, 1982:3:13-25.

8 Samren EB, van Duijn CM, Koch S, et al. Maternal use of antiepileptic drugs and the risk of major congenital malformations: a joint European prospective study of malformations: a joint European prospective study of
human teratogenesis associated with maternal epilepsy. Epilepsia 1997;38:981-90.
9 Gaily E, Granstrom ML, Hiilesmaa V, et al. Minor anomalies in the offspring of epileptic mothers. I Pediatr 1988:112:520 9 .

10 Koch S, Losche G, Jager-Roman E, et al. Major and minor birth malformations with antiepileptic drugs. Neurology 1992:42(suppl 5):83-8.

11 Yerby MS, Leavitt A, Erickson DM, et al. Antiepileptics and the development of congenital anomalies. Neurology 1992; 42(suppl 5):132-40.

12 Lindhout D, Schmidt D. In utero exposure to valproate and neural tube defects. Lancet 1986;i:1392-3.

13 Rosa F. Spina bifida in infants of women tested with carbamazepine during pregnancy. N Engl F Med 1991;324: 674-7.

14 Hanson JW, Myrianthopoulos NC, Harvey MAS, et al. Risks to offspring of women treated with hydantoin anticonvulsants, with emphasis on the fetal hydantoin syndrome. $f$ Pediatr 1976:89;662-8.

15 Jones KL, Lacro RV, Johnson K, et al. Patterns of malformations in the children of women treated with carbamazepine during pregnancy. N Engl f Med 1989;320:1661-6.

16 DiLiberti JH, Farndon DA, Dennis NR, et al. The fetal valproate syndrome. Am f Med Genet 1984;19:473-81.

17 Clayton-Smith J, Donnai D. Fetal valproate syndrome. $\mathcal{F}$ Med Genet 1995;32:724-7.

18 Delgado-Escueta AV, Janz D. Consensus guidelines; preconception counselling, management and care of the pregnant female with epilepsy. Neurology 1992;42:149-60.

19 Report of the quality of standards subcommittee of the American Academy of Neurology. Practice parameter management issues for women with epilepsy (summary statement). Neurology 1998;51:944-8.

20 Zahn C. Neurological care of pregnant women with epilepsy. Epilepsia 1998;39 (suppl 8): S26-S31

21 Spiedel BD, Meadow SR. Maternal epilepsy and abnormalities in the fetus and newborn. Lancet 1972;ii:839-43.

22 Nakane Y, Okuma T, Takahashi R, et al. Multi-institutional study on teratogenicity and fetal toxicity of antiepileptic drugs: a report of a collaborative study group in Japan. Epilepsia 1980;21:663-80.

23 Kaneko S, Otani K, Fukushima J, et al. Teratogenicity of antiepileptic drugs: analysis of possible risk factors. Epilepsia 1988;29:459-67.

24 Battino D, Binelli S, Caccamo ML, et al. Malformations in offspring of 305 epileptic women: a prospective study. Acta Neurol Scand 1992;85:204-7.

25 Rosser EM, Wilson LC. Drugs for epilepsy have teratogenic risks [letter]. BMF 1999;318:1289.

26 Gaily E, Granstrom ML. Minor anomalies in children of epileptic mothers. Neurology 1992;42(suppl 5):128-31.

27 Vanoverloop D, Schnell RR, Harvey EA, et al. The effects of prenatal exposure to phenytoin and other anticonvulsants on intellectual function at 4-8 years of age. Neurotoxicol teratol 1992;14:329-35.

28 van der Pol MC, Hadders-Algra M, Huisjes HJ, et al. Antiepileptic medication in pregnancy: late effects on the children's central nervous system development. Am $f$ Obstet Gynecol 1991;164:121-18.

29 Ornoy A, Cohen E. Outcome of children born to epileptic mothers treated with carbamazepine during pregnancy. Arch Dis Child 1996;75:517-20.

30 Majewski F, Steger M, Richter B, et al. The teratogenicity of hydantoins and barbiturate in humans, with consideration
on the aetiology of malformations and cerebral disturbances in the children of epileptic parents. Biological Research in Pregnancy 1981;2:37-45.

31 Beck-Mannagetta G, Janz D. Data on psychomotor and mental development in children of epileptic parents: a retrospective study. In: Janz D, Dam M, Richens A, et al, eds. Epilepsy, pregnancy and the child. New York: Raven Press, 1982:443-5.

32 Hill RM, Verniaud WM, Rettig GM, et al. relation between antiepileptic drug exposure of the infant and developmental potential. In: Janz D, Dam M, Richens A, et al, eds. Epilepsy, pregnancy and the child. New York: Raven Press, 1982: 409-417.

33 Shapiro S, Slone D, Hartz SC, et al. Anticonvulsants and parental epilepsy in the development of birth defects. Lancet 1976;i:272-5.

34 Latis GO, Battino D, Boldi B, et al. Preliminary data of a neuropediatric follow up of infants born to epileptic mothers. In: Janz D, Dam M, Richens $\mathrm{A}$, et al, eds. Epilepsy, pregnancy and the child. New York: Raven Press, 1982:419-23.

35 Granstrom ML. Development of the children of epileptic mothers: results from the prospective Helsinki study. In: Janz D, Dam M, Richens A, et al, eds. Epilepsy, pregnancy and the child. New York: Raven Press, 1982:403-8.

36 Vert P, Deplay MF, Andre M. Follow up study on growth and neurologic development of children born to epileptic mothers. In: Janz D, Dam M, Richens A, et al, eds. Epilepsy, pregnancy and the child. New York: Raven Press, 1982:43336.

37 Jager Roman S, Fating D, Koch S, et al. Somatic parameters, diseases and psychomotor development in the offspring of epileptic parents. In: Janz D, Dam M, Richens A, et al, eds. Epilepsy, pregnancy and the child. New York: Raven Press, 1982:425-32.

38 Nomura Y, Takabe Y, Nomura Y, et al. The physical and mental development of infants born to mothers treated with antiepileptic drugs. In: Sato T, Shinagawa S, eds. Antiepileptic drugs and pregnancy. Amsterdam: Excerpta epileptic drugs and preg
Medica, 1984;187-95. 
39 Fujioka K, Kaneko S, Hirano T, et al. A study of the psychomotor development of the offspring of epileptic mothers. In: Sato T, Shinagawa S, eds. Antiepileptic drugs and

pregnancy. Amsterdam: Excerpta Medica, 1984;196-206.
40 Hattig H, Helge H, Steinhausen HC. Infants of epileptic Hattig H, Helge $\mathrm{H}$, Steinhausen HC. Infants of epileptic
mothers: development scores at 18 months. In: Wolf P, mothers: development scores at 18 months. In: Wolf P, Dam M, Janz D, et al, eds. Advances in
New York: Raven Press 1987;579-581.

41 Gaily E, Kantola-Sorsa E, Granstrom ML. Intelligence of the children of epileptic mothers. F Pediatr 1988;113:66784.

42 Steinhausen HC, Losche G, Koch S, et al. The psychological development of children of epileptic parents. I. Study design

43 Scolnik D, Nulman I, Rovet J, et al. Neurodevelopment of children exposed in utero to phenytoin and carbamazepine monotherapy. fAMA 1994;271:767-70.
44 Leavitt AM, Yerby MS, Robinson N. Epilepsy in pregnancy: developmental outcome of offspring at 12 months. Neurology 1992;42 (suppl 5):141-3.

45 Losche G, Steinhausen HC, Koch S, et al. The psychological development of children of epileptic parents.II. The differential impact of intrauterine exposure to anticonvulsant drugs and further influential factors. Acta Paediatr 1994;83:961-6.

46 Koch S, Jaeger-Roman E, Losche G, et al. Antiepileptic drug treatment in pregnancy: drug side effects in the neonate and neurological outcome. Acta Pediatr 1996;85:739-46.

47 Jacoby A, Baker GA, Steen N, et al. The clinical course of epilepsy and its psychosocial correlates: findings from a UK community study. Epilepsia 1996;37:148-61.

48 Ohtsuka Y, Silver K, Lopes-Cendes I, et al. Effect of antiepileptic drugs on psychomotor development in offspring of epileptic mothers. Epilepsia 1999;40(supp12):296. 